\section{Mar Adentro: Haunting Ability, Masculinity, and Human Rights}

\author{
KOME - An International Journal of Pure \\ Communication Inquiry \\ Volume 7 Issue 1, p. 98-109. \\ (C) The Author(s) 2019 \\ Reprints and Permission: \\ kome@komejournal.com \\ Published by the Hungarian Communication \\ Studies Association \\ DOI: 10.17646/KOME.2019.11
}

\title{
Susan Flynn
}

University of the Arts London, London College of Communication, UNITED KINGDOM

\begin{abstract}
Ramón Sampedro, a former seaman and later poet, died in 1998. Now having passed the twentieth anniversary of his death, his work and life return to the spotlight with the attendant issues of disability, trauma, agency and end-of-life. The film Mar Adentro or, The Sea Inside (Amenábar, 2004), provides a lens with which to view some familial and cultural resonances of disability trauma. This paper critiques the ideological underpinnings of the film, suggesting that the film is haunted by ableist notions of the body. Garland-Thomson's notion of the misfit (2011) is employed to illustrate how the central character is portrayed as a borderline figure between life and death. Kristeva's abjection theory is used to illustrate how the beach is used as a borderline which demarcates the hero's subject/abject position. This paper hypothesises that the use of the beach as metaphor and the use of Galicia as a 'haunted' space, encourages the audience to understand persons with disabilities as 'neither here nor there'; rather, as 'not quite human beings'.
\end{abstract}

Keywords: Spanish film, Galicia, right-to-die, euthanasia, disability, abjection.

\section{Introduction}

"Sea inside, sea inside

In the weightlessness of the bottom

Where dreams come to fruition

Two wills unite

To realize a wish"

-Ramón Sampedro

The film opens with the sound of breathing. 'Now imagine a movie screen opening up before you' says a disembodied female voice while out of the haze a screen emerges and expands to fill the frame, showing a beach and calm sea. Ramón is in his mid-fifties, bald and pallid, living in a bedroom in the family home and cared for his brother's family. A ship mechanic in 
his past, Ramón is seen in flashback as a strapping muscular youth with thick black hair. On a beach outing, distracted by thoughts of his beautiful girlfriend, Ramón dives into shallow waters and is paralysed; his overt masculinity at once the apparent cause of his accident and the ongoing immobility. At the temporal point of the film, it has been twenty eight years since Ramón's accident, and since he has seen the sea. Ramón is now physically confined to the the Sampedro home, outside of the provincial capital of A Corun a, near a small town named Boiro. There he lives in a bedroom of the dark old farmhouse, without any near neighbours, tended by his sister-in-law Manuela. Ramón appears to attract an assortment of curious visitors, one of these, Rosa, a single mother, develops deep feelings for him. An attorney from the 'Death with Dignity' group, Julia, herself suffering from an incurable and degenerative condition, becomes Ramón's diegetic love interest. Swept up in his love of opera, his poetic writings, and his good spirits, Julia becomes drawn to Ramón. However, he proceeds with his quest to legally end his life and Julia is left behind, her own health and mental capacities deteriorating.

The film, I suggest, is haunted by ableist notions of the body. In modern cultural production, the forms of agency and subjectivity available to those who are outside the hegemonic 'norm' are often limited; fiction and film are most often created with a mainstream audience in mind and thus can be read as deeply ableist. 'Ableism' refers to the set of beliefs, processes and practices that disability activists have sought to challenge under the rubric of the social model of disability. Investigating ableism does not focus on the construction of disability or impairment per se, but draws attention to the production of a supposed ideal self and body (Campbell, 2009), thus emphasising that disability is socially produced. Interrogating instances of ableism in characterisation and in fictional plots calls for an examination of how (unearned) privilege attaches to those who can conform to the supposed norm. Such a lens interrogates the status quo as opposed to seeking the 'inclusion' of disabled people within extant social structures. The 'dream' of being restored to able-bodiedness and thus enacting a romantic relationship with Julia suggests an ableist stance. Ramón meets Julia in his dreams, flying from his bedroom window across the Galician fields and hills to reach the windswept beach where she is waiting. In this magnificent dream sequence, the audience is placed inside his body while he dreams he is flying and the land moves beneath us to the sound of frantic swish-panning, suggestive of a hurry.

Ramón: When I'm in the mood, I concentrate and walk I out to the sea. I fly there.

These illusions, common in much of Amenábar's work, serve to highlight the centrality of imagination to our lived experiences while also clearly placing the subject position of the disabled character in the imaginary. The audience is suspended in the moment of flight, vicariously escaping the heavy immobile body of the hero. Flight is a common theme in disability related film as the character associates outdoor open spaces with the freedom of movement which he lacks (Avatar, 2009; The Boy Who Could Fly, 1986; Birdy, 1984). The use of positive parallax (the illusion of space behind the screen plane) spectacularly depicts the exhilaration of movement, escape, and flight.

Soaring through space... has historically been associated with progress and mastery, both literally and metaphorically, and thus can be used to structure the overall journey of a heroic protagonist. (Ross, 2012: 211)

In this film, the dream of flight is not tethered simply to an explicit wish for mobility, agency and able-bodiedness, but to the freedom and the state of youthfulness and virility that death will supposedly bring. Flight also allows the protagonist to escape the weighty and glum 
reality of the old dark Galician farmhouse. This dream-state positions Ramón in a ghostly self; he is neither real nor unreal, operating on the edges of existence. On reaching the beach in this sequence, we find Julia bathed in the hazy glow of sunset, and Ramón's tall frame for the first time bends down over her. In the dream-state Ramón thus overcomes the trials of disability and this provides a narrative arc that at once exposes and reinforces embedded ideologies of the body.

\section{Galicia as haunted space}

Galicia has often been depicted as bound by its premodern past, occupying a space in the Spanish imaginary as the dark, rainy, and pagan periphery which is a purgatory, or, a space between life and death. (The Ancines Woods, 1970; The Flower of Holiness, 1973; Divinas Palabras, 1987; Immortal Sins, 1991; La leyenda de la doncella, 1994; Dagon, 2001; Thirteen Chimes, 2002; The Beach of the Drowned, 2015). This is seen to be because of its perceived lack of political autonomy within Spain, as Baretto writes:

As an immense corpus of sociological and anthropological writing can attest, even Galician folklore is populated with fantastic and otherworldly figures such as meigas, a nimas, the Santa Compan a, and trasnos the witches, wandering penitent souls, ominous apparitions, and mischief-makers who blur the boundaries between life and death. While it may have originated far in the past, the idea that Galicia is a land inhabited by the living and the dead continues to capture the imagination of writers and directors alike. (Barreto, 2011)

Galicia can be thus read as a haunted space, not just in its foregrounded mythic allusions, but also by its cultural and political separateness. Galicia, standing apart from the rest of Spain with its distinct dialect, customs and history, can be seen as not fully part of Spain but not fully autonomous, as such the film refers to a contested space, a space where distinction between life and death is ambiguous. "Cinema made in Galicia, then, can be said to exemplify this indeterminate state between life and death" (Barreto, 2011). While Ramón is not penitent, the flashback sequences suggest a yearning for a re-establishment, for belonging to the 'active' world. The tension between dependency and autonomy is played out in the subtle and nuanced relationship between Ramón and Manuela. The issue of autonomy within the film, can be seen thus to allude to the quest for autonomy of Galicia itself, and the need to reconcile the opposing forces of dependence and autonomy, tradition and modernity, and the regional and national within a postmodern Spanish state.

The melancholic depiction of Galicia with its farmhouses and windswept rural expanse, contributes to the positioning of Ramón in a state of hopelessness. Loureiro argues that unlike other Iberian nationalisms, Galician nationalism "follows the logic of melancholy" (2003) and has had to draw excessively upon myth rather than recent history in order to differentiate itself from the Spanish state. For Loureiro, the conversion of "Negra sombra" by Rosal' ia de Castro into Galicia's "de facto anthem, [. . .] a poem about radical lack and absence"' (167) is proof of the degree to which Galician identity is afflicted with melancholia. Used as the theme song of the film, the song posits Galicia and by default its citizens, as melancholic, and as such, lacking, unsettled and yearning.

Interpreting Ramón as a metaphor for Galicia, the movie permits us to think of the Galician subject as a living cadaver, and the decision to live or die as one of political autonomy (Baretto, 2011). Despite the apparent love shared between Ramón and his family, his enclosure within the four walls of the family home is emblematic of the stasis of 
characters with disabilities in popular culture. Traditionally, film represents disabled characters in stasis in relation to both the action and in relation to the other characters (Longmore 1987; Couser 2006). Such a directorial choice reinforces ableist ideologies by contending that the able-bodied do most of the action, while the disabled look on. The scene or architecture surrounding them is at odds with the limits of their mobility, the architecture forming a metaphor for a feeling of entrapment. This dynamization of space and place has the potential to create and sustain the sensation of isolation.

Disability again results in separation from the community...It is portrayed as the inevitable consequence of a serious physical impairment that prevents normal functioning, normal relationships, and normal productivity. (Longmore, 1987:69-70)

The movement, placing and body language of the disabled character has the power to acknowledge power relationships between him and other characters. The entrapment ends briefly when Ramón travels by minibus to Spain's capital for his legal battle for the right to die. In this, his journey moves from the personal to the political. Looking out the window during his bus ride, Ramón sees the average Spanish man and woman in various vignettes of daily life. The bus itself demarcates the outside from the inside, and its journey marks the brevity of Ramón's existence in the everyday realm. Such an overt use of allegory alludes repeatedly to the separateness and the 'otherness' of the character who has disability.

The film's polemic is foregrounded further when, in another instance of allegory, religion is set to war with the secular. A priest who is also quadriplegic visits Ramón in an attempt to convince him to drop his legal battle to end his life voluntarily. Unable to gain access to the upstairs room where Ramón is bed-bound, the wheelchair-bound priest engages in a comic upstairs-downstairs debate on religious rhetoric with Ramón, who retorts: "After we die, there's nothing, just like before we were born." Paradoxically, Ramón seeks institutional approval for his right to die, yet refuses to remain part of society or accede to partial agency through use of a wheelchair. There is further complexity as Ramón is disinterested in the praise for his poetry, yet allows it to be published to further his cause. Gaining the approval of the literary world, he takes up a symbolic position as a maker of meaning, yet he does so knowing that his meaning as such will forever be frozen after his death. Acceding to the symbolic realm with the publication of his book, Ramón allows the book to exist after him; a haunting of his story.

\section{Misfitting}

Disability life narratives have the potential to counter the pathologizing and marginalizing representations of disability (Couser, 2006). However, this narrative privileges mobility and able-bodiedness, making it the ultimate quest and the stuff of dreams. Mobility is very real in Ramón's dreams, the endless movement of the sea in contrast to the heavy immobile land on shore. Ramón does not reach the sea, however, and does not engage in a sexual relationship with Julia, choosing death instead, and the freedom from limitation which it brings.

[He] intransigently insists that he can have no post-impairment sexual life, even though several fabulous women offer themselves up to him as lovers in the film. The film actually suggests that his dogmatic asexuality is one of the chief motivations of his decision to commit suicide. (Garland-Thomson, 2007:122) 
As a misfit, he places himself outside the realm of the active subject and so he is restricted to the sea inside; the world of memory and imagination where he 'learns to cry with a smile'. At the end of the film his words "I'll be in your dreams" clarify that the place where he feels he now belongs is across the border in death. Garland-Thomson (2011) introduces the concept of the 'misfit', a feminist materialist disability concept, to articulate the manner in which the lived identity of disability is fixed in place and time. As Ramón chooses not to have a future life, he bases himself in the imaginary scenario of the seaside, the beach which demarcates the line between immersion in new experiences and the heavy ground which weighs him down in his present form. Ramón is caught at the borderline which Kristeva (1982) calls the point of 'abjection'. This paper employs intersections between these two schools of theory while exploring how the sea is used as a metaphor for a virile masculinity, while also providing a means by which the viewer can blame Ramón for his own predicament, first by jumping into the shallow sea and becoming disabled, then by failing to jump into the metaphorical sea of active sexuality.

I suggest that Ramón's failure to enact a 'disabled' sexuality results in his castaway status and ultimately his wish to die. Staying on the beach; the border between past and present, between sexual activity and inactivity, casts Ramón in an individualistic position where improvement depends on his own ability to psychologically overcome; just as in traditional disability narratives where the disabled character must enact the correct amount of self-drive to improve his own position (Norden, 1994; Garland-Thomson, 1997; Darke, 1998; Reeve, 2012). The film effectively masks the myriad social processes which are implicated in the construction of a disability, by placing Ramón's failure to engage in a sexual relationship with Julia at the centre of his alienation from a 'dignified human life'. Ramón refuses to submit to his feelings for Julia and maintain a relationship, so the film depicts him as the master of his own fate. He is depicted as oppressed as a result of his own actions and the psychological inability to move forward with the relationship opportunity rather than being oppressed by the complex web of social, institutional and cultural structures.

According to the social model of disability, disability oppression is created and sustained by attitudes and symbolic barriers, what Garland-Thomson calls 'exclusionary institutions'

I propose the term misfit as a new critical keyword that seeks to defamiliarize and to reframe dominant understandings of disability. Fitting and misfitting denote an encounter in which two things come together in either harmony or disjunction. When the shape and substance of these two things correspond in their union, they fit. A misfit, conversely, describes an incongruent relationship between two things: a square peg in a round hole. (Garland-Thomson, 2011: 593)

The notion of the misfit applies to Ramón in this narrative as his identity is extraneous to normative social behaviour. People with disabilities become misfits in terms of social attitudes but also in terms of material limitation (ibid). Not wishing to use a wheelchair, the four walls of the bedroom mark the boundaries of physical life. The limitation of domestic space which Ramón experiences becomes the metaphoric enclosure of his desires; he cannot break free and get to the sea of his desires. "Misfit, then, reflects the shift in feminist theory from an emphasis on the discursive toward the material by centering its analytical focus on the constituting relationship between flesh and environment" (ibid: 594). Ramón's fleshy body is unable to articulate his psychic desires; he fails to try to enact his feelings for Julia and instead choses to dream of the beach; the borderline between thinking and doing. He is unable to configure his notion of proper masculinity, the material body he has and the spaces 
in which he is now confined. As Garland writes, a misfit occurs when the environment does not sustain the shape and function of the body that enters it. (2011: 593)

$\mathrm{He}$ chooses this borderline space rather than 'diving in' to the sea and immersing himself in the realm of the living, loving subject. By choosing this borderline space, Ramón is implicated in his own 'abjection'; he rejects the opportunities for love which would bring him back into the realm of active subject. Julia Kristeva wrote of this 'borderline' in her work, Powers of Horror. Her work, as part of a body of psychoanalytical feminism with precedence in object-relations theory, discusses the agency and subjectivity that are available to 'others'.

In Powers of Horror, Kristeva uses the term 'abjection' for that which does not respect borders, positions and rules and that which disturbs identity, system and order (1982:4). The abject is placed on the side of the feminine, as opposed to the paternal, rulegoverned symbolic order. Thus the disabled can be affiliated with the feminine as disability's power to disenfranchise individuals lays them vulnerable to patriarchal domination. Kristeva suggests that a woman is limited within the frontiers of her own body and so feels exiled both by the general consensus and by the powers of generalization intrinsic to language. We can surmise that disabled hero experiences such alienation. In this sense, the disabled body is neither fully constituted, nor has the power to 'make meaning' and so as a form of corporeal alterity, is abject. Abjection is the subject's and cultures revolt against the corporeality of subjectivity- its material dependence on others. The corporeal alterity of Ramón's disabled body may be seen as a reminder of that which the subject rejects. Infantilized by the care he receives from Manuela, he lingers in this abject position, wishing for the mobility of his youth but choosing death over immobility. The disabled body can be viewed as a bodily alterity, an organic mutation which is abject to the whole organic subject who functions normally in the realm of the subject. He has already been rejected by his fiancée, who, it seems, took little encouragement to 'move on' and feels incapable of committing to Julia and engaging in a romantic relationship. He chooses his abject status himself; faltering at the line between life and death. The abject threatens life and must be radically excluded from 'life'; either brought back across the border to the place of the subject or mortally excluded.

Although the subject must exclude the abject, the abject must, nevertheless, be tolerated for that which threatens to destroy life also helps to define life. Further, the activity of exclusion is necessary to guarantee that the subject take up his/her proper place in relation to the symbolic. (Creed, 1993:11)

The symbolic order is separated from that which threatens its stability as the disabled body becomes 'abject' and is allowed a crossing across the boundary only by either assimilation or death. The film in this way asserts the subject position of the able-bodied normative; the disabled body is abjectified and denied 'normativity'. Ramón seeks social and institutional recognition and approval for his cause, yet he refuses to remain part of society or accede to partial agency through a wheelchair. In this way, symbolically he wishes for the subject position and reveres the institutions of the normate subjects. He is disinterested in the praise for his poetry, yet allows it to be published to further his cause. In some sense he accedes to the symbolic realm with the publication of his work; gaining the approval of the literary world he takes up a temporarily symbolic position as a maker of meaning even though he wishes to reject the role of subject by wishing to die. In this complex position, Ramón wrestles with his status as both abject and subject. He experiences both yet rejects both, a subject-in-process, acting out the psychological process of the subject struggling to come to terms with the abject within it. 


\section{Disability politics}

The Sea Inside, at first glance, seems to argue for the rights of the disabled Ramón to have authority to decide whether he lives or dies; "life is a right, not an obligation." However, the choice of 'death with dignity' removes Ramón from the world in which he may have made further impact.

Of course, there is undoubtedly something productive happening when mainstream films begin to challenge the stereotype of the feminized or asexual male quadriplegic...But these liberatory representations are accompanied by a set of political limitations that demand greater scrutiny. (Barounis, 2009)

The liberatory representation in this case is a thinly veiled reconstitution of the traditional medical model notion that disabled men are asexual. Ramón removes himself from the complicated position of a potentially active disabled subject when he says "I want to die because I feel that life in this condition has no dignity." Throughout his political struggle to gain this right, Ramón received much public notoriety, a status which precludes 'fitting'.

A reasonable fit in a reasonably sustaining environment allows a person to navigate the world in relative anonymity, in the sense of being suited to the circumstances and conditions of the environment, of satisfying its requirements in a way so as not to stand out, make a scene, or disrupt through countering expectations. (GarlandThomson, 2011:596)

Social capital is conferred by the ability to access spaces and establish relationships (ibid.) yet it is Ramón who refuses to regularly use a wheelchair and rejects the possibility of sustaining a relationship with Julia. In this way, society is 'let off the hook' and the misfit is not brought across the borderline into the realm of active subjects, but rejects it himself.

Mar Adentro stays aligned to the factual story and so its trajectory is constrained within factual boundaries. As such, it is not a liberatory film nor does it seek to align itself with disability rights movements. The romantic element might otherwise have been an opportunity to further social model discourse, rather than a denial of sexual possibilities for Ramón:

Ramón: You're sitting there, three feet away, but for me those three feet are an impossible journey.

Wilkerson (2002) exposes the power of medical discourse in the denial of sexual agency to disabled people and shows how disability's perspective has the potential to "be a key component of the liberation struggles of all disenfranchised groups" (2002: 37). New documentary cinema cultivates a disability-identified perspective, a bona-fide disability cinema (Mitchell and Snyder, 2006). Such theory celebrates the subversive potential of new documentary cinema. In these life narratives, the disabled characters have the potential to invent or reinvent themselves in a way that was not possible before. Carving out distinctive identities, such characters reveal assimilation into mainstream society as condescension. Film has had more success than other art forms in this regard; while still not accessing 'mainstream' audiences, new documentary cinema is growing in popularity and 'crosses over' to popular film audiences on some occasions, as seen in the success of Murderball (2005). 
The Disability Arts movement is tethered to both the new forms of disability documentary film and the ethos of transgressive renaming. The emergence of Disability Arts culture was engaged with the political disability movement of the 1970s and 1980s (Darke, 2003: 132). Using 'art' to explore disabling practices, Disability Art seeks to engage the social model of disability, illustrating the cultural barriers to equality and the lived experience of disability. However, as Darke suggests, the movement has failed to penetrate 'mainstream' culture and remains at the margins, having become "a tool of the 'hidden forces' used against disabled people to legitimize their (our) continued mass exclusion from not just art culture but culture more widely" (ibid: 141).

Some disability-film theorists now see disability's representation as a tool for exposing or interrupting the fallacy of the normate and the current ideologies. McRuer (2010) uses disability in the films Million Dollar Baby (2004) and Murderball (2005) to critique neoliberalism. He invokes the potential romance between Maggie and Frankie in Million Dollar Baby, suggesting that the film is haunted by "a proper sexuality that would provide stability in a world made unstable by the cultural, political, and economic dislocations of the last three decades" (2010: 172). McRuer, a self-styled 'crip theorist', explores propriety, respectability and normalcy, showing that they are in fact fallacies, which ultimately need to be exposed as such. In much of his work we are reminded that human differences cannot and should not be shoe-horned into a homogenizing of human beings, the dangerous heteronormativity and compulsory able-bodiedness that is constantly reaffirmed in film. Mar Adentro, through its fantasy of the sea and of the beach as border, risks glorifying that homogenization; sentimentality for the ability of youth and the freedom of movement is deleterious for persons with disabilities and alternative material abilities.

While the motif of the sea is used to create nostalgia in the narrative, it at once implicates both release from disability and physical 'able' activity, both reconstituting ideologies of normalcy. The 'normal' is the producer of pathology (Davis, 1995), so that disability then is a product of a set of social relations, a result of the normal's creating itself as average. This 'normal' is thus the perfect model against which all bodies must be measured and it is assumed, to which all bodies aspire. Davis exposes the idea of normalcy as inherently flawed. In 'Nude Venuses, Medusa's Body, and Phantom Limbs', Davis (1997) develops this theory of normalcy, suggesting that in film, in particular, the normal body is enforced and the 'phantasm' of the body is subjected to normativizing processes. Disability forms one half of the binary, the negative space, a result of a dialectic formed by social conditions and hegemonic forces. Mar Adentro, it could be said, is haunted by this phantasm of the normal body and utilizes the dreams of the hero to promote the attractiveness of the lost state of ability. Ramón himself seems to privilege the able body; looking back to the viewer in a nod to normalcy as he leaves his bedroom in the flying dream sequence.

\section{The sea as metaphor}

The sea has been out of Ramón's sight for twenty eight years, yet his imagined journeys take him there. Swishing through the sky he imagines flying to the beach where the salty haze and windswept shore enact many of the sensations he cannot now experience. The sea is utilised as a metaphor for all that is lost, and the place where the hero could return in death; the site of his rebirth into ability. He relives the moment of his accident in the sea, yet he is drawn back to it in his dreams; it is at once the scene of loss and the scene of retrieval.

Julia: Too bad there's no view of the sea.

Ramón: Just as well. This way I see it when I choose. 
The sea's use as a metaphor masks the ableist agenda of the choice between longing to be 'able' and death; "[m]etaphor, it is argued, dresses illness in an allusive language, which allows it to appear through a distorting lens and distances the reader or viewer" (RiveraCordero, 2013).

Ramón rejects a wheelchair as to him it is a reminder of all that is 'lost' and he refuses the 'otherness' it would give him. Instead, he lingers in dreams and memory, the sea always present, along with his 'lost' virility, youth and ability. "Ramón portrays a character whose "use" in the film is to preserve an ideology of superior masculinity and assumed wholeness" (Markotic, 2012). Flashbacks of the diving accident occur on three occasions during the narrative, marking this as a pivotal moment of immersion. The third depiction of the accident however, occurs at the moment when Ramón dies. In this version of the memory he is not pulled from the water back to life, but lies inert underwater, submerged in his masculine virility and subjectivity. His wish to die is a wish to return to that state of 'wholeness' at the point where he makes the decision to dive in. Death becomes the dream of return to the sea and the able body of his youth and so at the close of the film he stays underwater.

The film opens with Gene, Ramón's social worker urging him to relax, as he dreams of the sea. The end of the film, however, is narrated by Ramón's own voice, in his letter to Julia. In this way he has finally achieved his 'voice', returned to the sea and reclaimed his masculine power. The actual and metaphorically fluid nature of the sea accommodates Ramón's virile self; it is the material environment he chooses and that which he dreams of, the place where he 'fits'.

Julia is already at the beach, already suffering from CADASIL, a degenerative condition. Symbolically, she remains at the beach at the end of his dream and the film concludes with her at her beach house, being visited by friends. The friends bring her a letter from Ramón, but she does not recognise his name; she chose not to take her own life and so she is now the visual representation of the choice Ramón did not make. She fits here at the beach house, now trapped at the beach/border between active and inactive life, separated from the possibility of immersion in real life; confined to bed, the window to the sea marks the parameter of her existence. Just as Ramón could not physically reach the sea, so Julia cannot now mentally reach it. The sea is again a metaphor for the virility of youth and the robustness of health.

Sontag reminds us that metaphorical discourse on illness and disability does something else as well: it renders a physical or psychological state politically and socially potent in a way that threatens to exclude the ill and the disabled. When the norm to be defended is presented as a certain kind of health, those who experience disability or disease are seen as abnormal and are subtly excluded. (Rivera-Cordero, 2013: 62)

While the misfits, Ramón and Julia, fall into devalued social categories, their own choices are shown to be the catalysts to their ultimate fates. Neither provide an inspiring story of 'overcoming' and it is ultimately a film which devalues what Garland-Thomson calls "instances of resourcefulness arising from misfits...the productive power of misfitting" (2011: 604). The beach and the sea, vulnerable to the elements and with their unstable material forms, become the best material fit for the misfits. The sea has traditionally been used as a metaphor for the unknown, the unstable and the all-encompassing. The power of sea imagery to inspire sensual memory has been harnessed by film makers throughout the history of the medium.

In the wake of this centuries-old tradition, contemporary cinema exploited the capability of water, visually and aurally, to give a palpable form to human desires and 
dreams. Water is often represented or evoked in film as a substance that submerges something that is destined to re-emerge. Through its semantic fluidity, cinema lets the unconscious drift before the eyes of the spectators and infiltrate their limpid gaze. A psychological malaise affects the main characters and has to be washed away with clean water. (D'Aloia, 2012: 91) The sea is the 'psychic' space where Ramón and Julia can consummate their affection and become engulfed by their senses. Its fluidity can accommodate their misfitting bodies and allow them to be their complete selves.

The sea also plays an important diegetic role in this narrative; it marks the shift in temporal order; before the dive and after the dive. Now, Ramón's passions are all 'at sea', tumultuous, in disarray and unfathomable, like the ocean. The viewer is drawn towards the sea as the narrative moves towards the euthanized ending which Ramón wants. The 'problem' of disability will essentially be effaced by this watery climax; the social structures which ought to accommodate Ramón will be excused as he will float out of sight or sink to the bottom of the spectators' consciousness.

The point is that water is not only a representational substance that effectively visualises and symbolises the characters' psychic condition, but also a substance in which the film characters' bodies are immersed or drown together with their troubles. The fluid properties of water find an expressive cinematic 'translation' in the choice of precise technical and stylistic solutions with which narrative mainstream contemporary cinema both physically and psychically engages the spectator in a 'water-based relationship'. (D'Aloia, 2012: 95)

The metaphor of the sea is in contrast to the actual physical limitation of Ramón's character in the bedroom of the family home. The mise-en-scene alludes to Ramón's confinement; the close-ups of his face providing the key to his emotions. The many encounters which occur in the room, as well as the dream sequences, dispel any possibility of the visual field appearing constricted however, just as the poetic close ups of symbolic artefacts point to the importance of art and culture in Ramón's life, such as the needle drawing on the vinyl record as it plays an aria. The mise-en-scene of the diving scene is a sepia-tinted memory much like an old photograph. The moment of immersion in the water, however, even twenty eight years later, is clear and lucid; the sea inculcates all of the senses, devouring the spectator in the moment. Physical human form is blurred by the water and the materiality of bodies is lightened, which masks the rejection of the disabled human body. Advocacy and rejection are simultaneously enacted by the wish to return to the metaphorical sea.

\section{Conclusion}

Mar Adentro, constrained by its faithfulness to the life story of Ramón, disavows disability rights' notions of the right to a full and rewarding life, instead foregrounding the hero's search for end-of-life advocacy. The film can, in this way, be read as engaging in an ableist privileging of 'normal' bodies and relationships; using the hero's dreams of the sea as a metaphor for lost physical ability and virility. Galicia, presented as a timeless but mystical terrain, is used as a highly suggestive location: trapped in this environment, the hero seizes the freedom of dreams to enact his true desires. As a misfit, the hero concentrates on his dreams and memories, rather than enact a subject position; he rejects the material possibilities of his body such as a romantic relationship and the use of a wheelchair, choosing instead to be haunted by his lost virility. Metaphorically, the border between ability and disability is enacted by the beach. He is 'abject' and so, Kristeva's purification process would suggest that 
if he cannot be made 'normal' and interact with everyone else he must 'cross over' and be free in death. The ethical complexities of such an approach are legion; recent work, such as that by Garden (2007) illustrates that patients' sociocultural and personal experience of illness is often at odds with (medical model) biomedical approaches. This results in a dichotomy of disease-centered care versus patient-centered care. Current debates in patient care question whether pathology is responsible for illness and disability or whether doctors and health professionals should focus on the patient's experience of illness. Medical humanities often suggest that the practice in patient care often contradicts any commitment to the patient's own experience and feelings, emphasizing scientific knowledge at the expense of symbolic and affective aspects of illness. (Garden, 2007:551-567)

The narrative thus demands sustained ethical reflection, which cannot be completely addressed in a paper of this length. However, the aim of this analysis has been to illustrate that while this narrative is complicated by the biographical stance of the film, the depiction has some quite deleterious implications for persons with disabilities. The final lines, Ramón's voiceover, confirm that love, virility and death will be attainable together.

Your gaze and mine, over and over like an echo, repeating silently: "Deeper, and deeper," beyond everything that is flesh and blood. But I always awaken and I always wish for death, my lips forever entangled in your hair.

\section{References}

Barounis, C. (2009) 'Cripping Heterosexuality, Queering Able-Bodiedness: Murderball, Brokeback Mountain and the Contested Masculine Body.' Journal of Visual Culture Vol 8 (1) 54-75. CrossRef

Barreto, D.M. (2011) 'Ir de morto, ir de vivo: GALICIANS IN A STATE OF LIVING DEATH.' Journal of Spanish Cultural Studies, Vol 12 (4) 385-399. CrossRef

Campbell, F. K. (2009) Contours of Ableism. New York: Palgrave McMillan.

Couser, T. G. (2006) 'Disability, Life Narrative, and Representation'. In: Davis, L. (ed.) Disability Studies Reader. New York: Routledge, 399-401.

Creed, B. (1993) The Monstrous Feminine: Film, feminism, psychoanalysis. London: Routledge.

Darke, P. (2003) 'Now I Know Why Disability Art is Drowning in the River Lethe (with thanks to Pierre Bourdieu)'. In: Riddell, S. and Watson, N. (eds.) Disability, Culture and Identity. Essex: Pearson Education, 131-142.

Davis, L. (1995) Enforcing Normalcy: Disability, Deafness, and the Body. New York: Verso.

Davis, L. (1997) 'Nude Venuses, Medusa's Body and Phantom Limbs: Disability and Visuality'. In: Mitchell, D.T. and Snyder, S.L. (eds.) The Body and Physical Difference: Discourses of Disability. Ann Arbor: University of Michigan Press, 51-71.

D'Aloia, A. (2012) 'Film in Depth. Water and Immersivity in the Contemporary Film Experience.' Film and Media Studies 2015 Vol 5, 87-106.

Darke, P. (1998) 'Understanding Cinematic Representations of Disability'. In: Shakespeare, T. (ed.) The Disability Reader. London: Cassell, 181-197.

Garden, R. (2007) 'The Problem of Empathy: Medicine and the Humanities' in New Literary History 38(3) 551-567. CrossRef

Garland-Thomson, R. (1997) Extraordinary Bodies: Figuring Physical Disability in 
American Culture and Literature. New York: Columbia University Press.

Garland-Thomson, R. (2007) 'Shape Structures Story: Fresh and Feisty Stories about

Disability.' Narrative Vol 15 (1), 113-123.

Garland-Thomson, R. (2011) 'Misfits: A Feminist Materialist Disability Concept.' Hypatia

Vol 26 (3), 591-608. $\underline{\text { CrossRef }}$

Kristeva, J. (1982) Powers of Horror. New York: Columbia University Press.

Longmore, P. (1987) 'Screening Stereotypes: Images of Disabled People in Television and

Motion Pictures'. In: Gartner, A. and Joe, T. (eds.) Images of the Disabled, Disabling Images. New York: Praeger, 65-78.

Loureiro, A. (2003) 'Imperfect Past: Globalization, Nationalism, and the Vanishing

Intellectual.' Arizona Journal of Hispanic Cultural Studies Vol 7, 161-72. CrossRef

Markotic, N. (2012) 'The Narrator Witness: Dis/Connections Between Disability and Death.'

The Review of Education, Pedagogy and Cultural Studies Vol 34 (3-4), 136-147. CrossRef

McRuer, R. (2010) 'Neoliberal Risks: Million Dollar Baby, Murderball and Anti-National Sexual Positions'. In: Chivers, S. and Markotic, N. (eds.) The Problem Body. Ohio: The Ohio State University Press, 159-177.

Norden, M.F. (1994) The Cinema of Isolation. New York: Routledge.

Reeve, D. (2012) 'Cyborgs, Cripple and the iCrip: Reflections on the Contribution of Haraway to Disability Studies.' In: Goodley, D., Hughes, B., Davis, L., Disability and Social Theory: New Developments and Directions. London: Palgrave, 91-111.

Rivera-Cordero, V. (2013) 'The Self Inside and Out: Authenticity and disability in Mar adentro and Yo, tambien.' Hispania Vol 96 (1), 62-70. CrossRef

Ross, S. (2012) 'Invitation to the Voyage: The Flight Sequence in Contemporary 3D Cinema', Film History Vol 24 (2): 210-220. CrossRef

Wilkerson, A. (2002) 'Disability, Sex Radicalism, and Political Agency', NWSA Journal Vol $14(3): 33-57$.

\section{Filmography}

Avatar (2009) Cameron, J. [Theatrical] $20^{\text {th }}$ Century Fox.

Birdy (1984) Parker, A. [Theatrical] Tri-Star Pictures.

Dagon (2001) Gordon, S. [Theatrical] Filmax International Spain.

Divinas Palabras (1987) García Sánchez, J.L. [Theatrical] Ion Films.

Flower of Holiness (1973) Marsillach, A. [Theatrical] Paramount Films de España.

Immortal Sins (1991) Hachuel, H. [Theatrical] Concorde-New Horizons.

La leyenda de la doncella (1994) Pinzas, J. [Theatrical] Atlantico Films

Mar Adentro [The Sea Inside] (2004), Amenábar, A. [Theatrical] Fine Line Features.

Million Dollar Baby (2004) Eastwood, C. [Theatrical] U.S.A.: Warner Bros.

Murderball (2005) Rubin, H.A. and Shapiro, D.A. [DVD] U.S.A.: MTV Films.

The Ancines Woods (1970) Olea, P. [Theatrical] Spain: Universal Films Española.

The Beach of the Drowned (2015) Herrero, G. [Theatrical] Foresta Films.

The Boy Who Could Fly (1986) Castle, N. [Theatrical] 20 ${ }^{\text {th }}$ Century Fox.

Thirteen Chimes (2002) Villaverde, X. [Television] Antena 3 Television. 